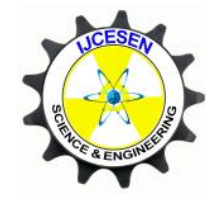

Copyright C IJCESEN
International Journal of Computational and

Experimental $\boldsymbol{S}$ cience and Engineering

(IJCESEN)

Vol. 4-No.2 (2018) pp. 37-40

http://dergipark.gov.tr/ijcesen

Research Article

\title{
An Investigation on Radiation Protection and Shielding Properties of 16 Slice Computed Tomography (CT) Facilities
}

\section{Huseyin Ozan TEKIN ${ }^{1 *}$, Baris CAVLI ${ }^{2}$, Elif Ebru ALTUNSOY ${ }^{3}$, Tugba MANICI ${ }^{4}$, Ceren OZTURK ${ }^{2}$, Hakki Muammer KARAKAS ${ }^{5}$}

\author{
${ }^{1}$ Department of Radiotherapy, Uskudar University, Istanbul, Turkey \\ ${ }^{2}$ Affidea, Istanbul, Turkey \\ ${ }^{3}$ Department of Medical Imaging, Uskudar University, Istanbul, Turkey \\ ${ }^{4}$ Medical Radiation Research Center (USMERA), Uskudar University, Istanbul, Turkey \\ ${ }^{5}$ University of Health Sciences, FSM Education and Research Hospital, Istanbul, Turkey
}

* Corresponding Author : huseyinozan.tekin@uskudar.edu.tr ORCID: 0000-0002-0997-3488

(First received 21 March 2018 and in final form 18 May 2018)

Keywords

Radiation Protection

Computed Tomography

Radiation Shielding

\begin{abstract}
One of the fundamental principles of radiation protection is distance factor. In CT facilities maximum dose occurs near gantry and dose rate is decreases by distance. To know the rate of reduction of the amount of dose that distance is very important for radiation protection procedure especially for apply criterias of International Commission on Radiological Protection (ICRP) on radiation protection. This technical study aimed to investigate the backscattered dose amount from 16 Slice $\mathrm{CT}$ devices for verification of radiation protection measures in several CT facilities and also to evaluate the shielding properties of walls of operating room and patient waiting room. This technical study has been performed in Goztepe Education and Research Hospital, Umraniye Education and Research Hospital, Haydarpasa Education and Research Hospital, Beykoz Education and Research Hospital and Sancaktepe Education and Research Hospital, respectively. In this study, we measured the dose rates from the gantry until exit door and behind the door. The results showed that, backscattered dose amount has been decreased by distance. We obtained only background radiation in radiographer room and patient waiting room. The results showed also that radiation protection requirements are maximized in investigated hospitals. It can be concluded that, recent method can be applied for various CT facilities for optimum radiation protection studies which also in discussion with ICRP and IAEA for better radiation protection and shielding in radiology clinics.
\end{abstract}

\section{Introduction}

A Computerized Tomography (CT) scan associates a series of X-ray images obtained from different angles to create patient's cross-sectional body parts images. It can be used especially for bones, blood vassels and soft tissues. As a comparison between two device, provided information from the patient by using CT is greater then the normal plain X-ray device. Since CT uses various dose of X-ray for imaging of body radiation protection became a major topic in investigation areas. Computed tomography (CT) is an imaging method that produces cross- sectional images by representing in each pixel the local X -ray attenuation properties of the body. Since the introduction of helical computed tomography (CT) in the early 1990's, the technology and capabilities of CT scanners have changed tremendously. By the developing technology on diagnostic devices, procedures are performing with detailed informations about patient. The patient is placed between the source and detector, and the detector is configured with its geometric center located at the $\mathrm{x}$-ray source. In addition to various benefits of medical imaging by using $\mathrm{CT}$, of course there is some risk groups associated with the $\mathrm{x}$-ray 
radiation exposure. The possibility for absorbed $\mathrm{x}$ rays to cause cancer or inheritable mutations leading to genetically associated diseases in offspring is thought to be very small for radiation doses of the magnitude that are associated with CT process.

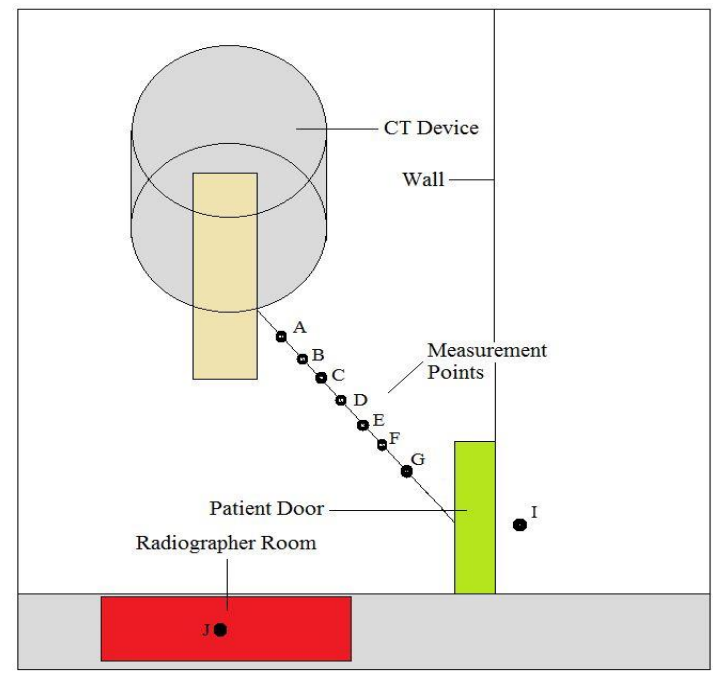

Figure 1. Schematic view of CT room

Under some rare circumstances of prolonged, highdose exposure, $x$ rays can cause other adverse health effects, such as skin erythema), skin tissue injury, and birth defects following in-utero exposure. There is some considerable absorbed dose rates from CT scan. Table 1 shows the dose a patient could receive during the procedure [1]. As we see from the table 1, values should be considered as which would cause biological effects. High-radiation exposure occurs during computed tomographic (CT) fluoroscopy [2]. This high rate of radiation is a condition that acceptable to the patient because of imaging procedure but we have to consider one other case that radiation dose around CT device that can be effect the CT operator or other staff. For the CT operator, exposure is primarily a function of scattered radiation and collimator or gantry leakage [3]. In past several years, some work has been done on this subject [4-7]. In this technical study, we aimed to investigate the backscattered dose amount from 16 Slice CT devices for verification of radiation protection measures in several CT facilities. This technical study has been performed in Goztepe Education and Research Hospital, Umraniye Education and Research Hospital, Haydarpasa Education and Research Hospital, Beykoz Education and Research Hospital and Sancaktepe Education and Research Hospital, respectively.

\section{Materials and methods}

In this study, we performed the measurements in CT device room, radiographer room and patient waiting room, respectively. Experimental measurements were obtained in the processes performed by GE520 (16 Slice) device for the same imaging parameters of CT Abdominal examinations which often performing by $120 \mathrm{kV}$. As a first step, we performed the measurements for 8 different location from CT gantry untill exit door. Figure 1 represents the measurements locations according to the position of the gantry.

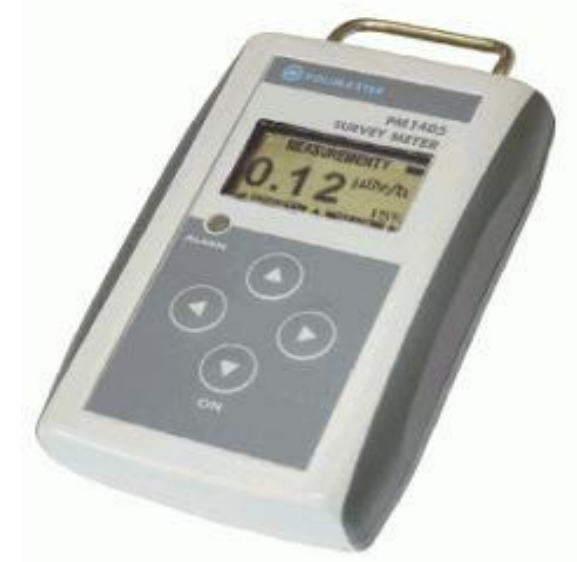

Figure 2. Polimaster Survey Meter PM1405

In figure $1 . \mathrm{I}$ is location of patient door, $\mathrm{J}$ is location of control room for radiographers. Moreover, the measurements points have been presented from A to $\mathrm{H}$, respectively. The measured dose values are given in table 2 with the ID of measurement points. All the dose measurements are performed by using the Polimaster Survey Meter (PM1405) shown in figure 2. Polimaster Survey Meter is compact multifunction and capable of measuring x-ray, gamma and beta radiation. We performed the simultaneous and selective measurement of the $\mathrm{x}$-ray radiation intensity by using PM1405 during Abdominal CT examinations. In this study, all the measurements were performed by using user interface of PM1405 in operating room by remote control with personal computer which comes with detector. Thus, no radiation risk has occurred during the measurements.

\section{Results}

We performed our measurements in seven different points from the gantry point by increasing $50 \mathrm{~cm}$ in each measurements. We considered the average dose rates in each distance. Table 3 gives the type of examination and $\mathrm{kV}$ values in different distances and the obtained dose values, respectively. 
Table 1. Effective dose rates due to examination

\begin{tabular}{|l|l|}
\hline Examination & Effective Dose (mSv) \\
\hline IVP & 2.5 \\
\hline Barium Swallow & 1.5 \\
\hline Barium Enema & 7.0 \\
\hline CT Head & 2.0 \\
\hline CT Chest & 8.0 \\
\hline CT Abdomen & 10.0 \\
\hline CT Pelvis & 10.0 \\
\hline Angioplasty & $7.5-57.0$ \\
\hline Coronary Angiogram & $4.6-15.8$ \\
\hline
\end{tabular}

Gamma radiation is the part of the electromagnetic spectrum. A gamma radiation ray not absorbed by the air, but its intensity decreases because it spreads out. Accordingly, the intensity changes with the inverse square of distance: it follows an inverse square law. As we see from the table 2, the dose rates decreased by the increased distance from CT gantry.

Table 2. Distance and dose rates

\begin{tabular}{|l|l|l|l|l|}
\hline Examination & $\mathrm{kV}$ & Distance & $\begin{array}{l}\text { Average } \\
\text { Measured } \\
\text { Dose } \\
(\mathrm{msV} / \mathrm{h})\end{array}$ & $\mathrm{ID}$ \\
\hline $\begin{array}{l}\text { CT } \\
\text { Abdominal }\end{array}$ & 120 & 20 & 48,5 & $\mathrm{~A}$ \\
\hline $\begin{array}{l}\text { CT } \\
\text { Abdominal }\end{array}$ & 120 & 70 & 13,2 & $\mathrm{~B}$ \\
\hline $\begin{array}{l}\text { CT } \\
\text { Abdominal }\end{array}$ & 120 & 120 & 8,5 & $\mathrm{C}$ \\
\hline $\begin{array}{l}\text { CT } \\
\text { Abdominal }\end{array}$ & 120 & 170 & 2,9 & $\mathrm{D}$ \\
\hline $\begin{array}{l}\text { CT } \\
\text { Abdominal }\end{array}$ & 120 & 220 & 1,95 & $\mathrm{E}$ \\
\hline $\begin{array}{l}\text { CT } \\
\text { Abdominal }\end{array}$ & 120 & 270 & 1,24 & $\mathrm{~F}$ \\
\hline $\begin{array}{l}\text { CT } \\
\text { Abdominal }\end{array}$ & 120 & 320 & 1,08 & $\mathrm{G}$ \\
\hline
\end{tabular}

Considering the clinical parameters, we also measured the dose rates in radiographer room and behind the patient door. The measurements showed that, average dose amount was between 0.07 and
$0,08 \mathrm{msV} / \mathrm{h}$. This value has been obtained as a background radiation around the hospitals. Therefore, one can say that, wall shielding of the radiographer room and the patient waiting room have provided maximum radiation protection considering the optimum radiation shielding requirements.

\section{Conclusion}

For decades, studies on radiation protection and radiation shielding for ionizing radiation have achieved great development especially by new generation shielding materials and dose reduction techniques. This study clearly showed that, radiation protection requirements and shielding properties in investigated hospitals are significantly optimized. it can be concluded that, recent method can be applied for various CT facilities for optimum radiation protection studies which also in discussion with ICRP and IAEA for better radiation protection and shielding in radiology clinics.

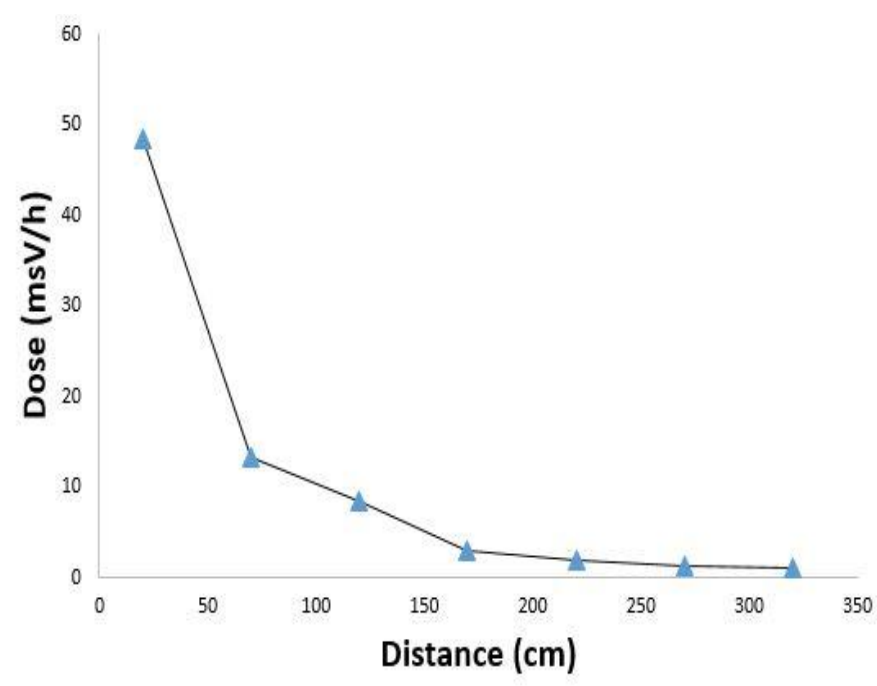

Figure 2. Comparison of distance and dose distribution

\section{References}

[1] Wall B.F., Hart D. Revised radiation doses for typical x-ray examinations. The British Journal of Radiology, 1997. 70: 437-439.

[2] Z. Neeman et.al., CT Fluoroscopy Shielding Decreases in Scattered Radiation for the Patiendt and Operator. J Vasc Interv Radiol, 2006 Dec; 17(12): 1999-2004.

[3] Stoeckelhuber BM, Leibecke T, Schulz E, et al., Radiation dose to the radiologist's hand during continuous CT fluoroscopy-guided interventions. Cardiovasc Intervent Radiol, 2005. 28:589-594

[4] D.Richard et.al.,.Patient and Personnel Exposure during CT Fluoroscopy-guided Interventional Procedures. RSNA Radiology V. 2000, 216 (1). 
[5] V.Every, R.J. Petty. Measurements of computed tomography radiation scatter. Australas Phys.Eng. Sci. Med.1992, 15(1) pp.15-24.

[6] Stoeckelhuber BM, Leibecke T, Schulz E, et al. (2005). Radiation dose to the radiologist's hand during continuous CT fluoroscopy-guided interventions. Cardiovasc Intervent Radiol. 28: pp. 589-594.

[7] M.Salvado et.al.,(2005). Monte Carlo calculation of radiation dose in $\mathrm{CT}$ examinations using phantom and patient tomographic models. Radiation Protection Dosimetry. 114(1-3):364-8. 